This item is the archived peer-reviewed author-version of:

Urban green infrastructure : a review on valuation toolkits from an urban planning perspective

\title{
Reference:
}

Van Oijstaeijen Wito, Van Passel Steven, Cools Jan.- Urban green infrastructure : a review on valuation toolkits from an urban planning perspective Journal of environmental management - ISSN 0301-4797 - 267(2020), 110603

Full text (Publisher's DOI): https://doi.org/10.1016/J.JENVMAN.2020.110603

To cite this reference: https://hdl.handle.net/10067/1694480151162165141 


\section{Urban Green Infrastructure: a Review on Valuation Toolkits from an Urban Planning Perspective}

Wito Van Oijstaeijen

Department of Engineering Management, Institute of Environment and Sustainable Development University of Antwerp, Belgium

wito.vanoijstaeijen@uantwerp.be

Steven Van Passel

Department of Engineering Management

University of Antwerp, Belgium

steven.vanpassel@uantwerp.be

Jan Cools

Institute of Environment and Sustainable Development

University of Antwerp, Belgium

jan.cools@uantwerp.be

\section{Graphical abstract}

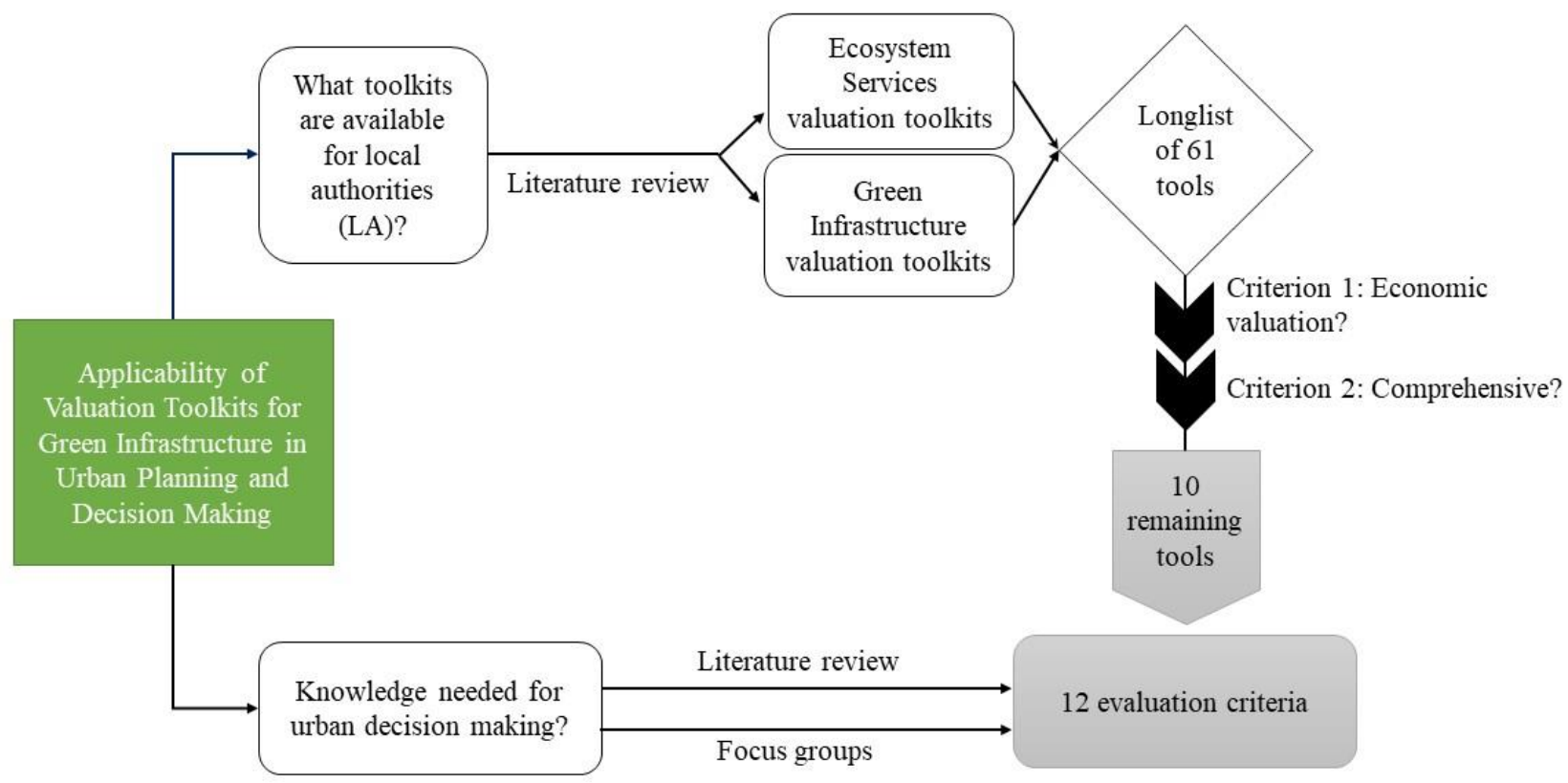

\section{Abstract}

As a response to increasing urbanization and changing weather and climatic patterns, urban green infrastructure (UGI) emerged as a concept to increase resilience within the urban boundaries. Given that implementing these (semi-) natural solutions in practice requires a clear overview of the costs and benefits, valuation becomes ever important. A range of decision-support tools for green infrastructure and ecosystem services exist, developed for various purposes. This paper 
reviews the potential of 10 shortlisted and existing valuation tools to support investment decisions of urban green infrastructure. In the assessment, the functionality is regarded specifically from the urban planning and decision-making viewpoint. The toolkits were evaluated on 12 different criteria. After analyzing the toolkits on these criteria, the findings are evaluated on the (mis)match with specific requirements in the urban planning and management context. Secondly, recommendations and guidelines are formulated to support the design of simple valuation tools, tailored to support the development of green infrastructure in urban areas. Approaching the valuation toolkits biophysically and (socio-)economically provides an integral overview of the challenges and opportunities of the capacities of each framework. It was found that most tools are not designed for the peculiarities of the urban context. Several elements contribute to the hampering uptake of GI valuation tools. Firstly, the limited effort in the economic case for green infrastructure remains a burden to use toolkits to compare grey and green alternatives. Secondly, tools are currently seldom designed for the peculiarities of cities: urban ecosystem (dis)services, multi-scalability, life-span assessments of co-benefits and the importance of social benefits. Thirdly, toolkits should be the result of co-development between the scientific community and local authorities in order to create toolkits that are tailor made to the specific needs in the urban planning process. It can be concluded that current tools, are not readily applicable to support decision making as such. However, if applied cautiously, they can have an indicative role to pinpoint further targeted and in-depth analyses.

\section{Keywords}

Green infrastructure; Urban green space; Valuation toolkit; Ecosystem services; Green infrastructure valuation; Urban planning

\section{Research highlights}

- Applicability of green infrastructure tools in urban planning was assessed.

- Toolkits don't succeed in comprehensively assessing urban green infrastructure.

- Lack of life-span assessments in tools impedes on credible economic case for UGI.

- Currently, toolkits and their use are not aligned with needs of their potential users.

\section{Introduction}

Within the reality that the impacts of climate change are affecting people on a more frequent basis every year, climate change adaptation has become a key topic in environmental sciences. On the same hand, rising urbanization causes cities to become increasingly dense and wide, most often at the expense of green areas. However, humans are still dependent on nature for their livelihood (Bolund \& Hunhammar, 1999) and human well-being and health is closely related to the availability of nature (Ward Thompson, 2011). The benefits of nature are often defined as the ecological functions it performs, where the ecosystem services concept then contributes to placing value on these functions (Ahern, 2007). With the publication of the Millennium Ecosystem Assessment in 2005 (Millennium Ecosystem Assessment, 2005), there has been continuous debate for the protection of ecosystem services provision. As a result of human dependency on ecosystem services and intensive urbanization, a paradox emerged between the supply and demand of 
ecosystem services. This led to the expansion of the ecosystem services debate from farmlands and ecosystems to cities and urban ecosystems (Rosenzweig et al., 2010). In our densely populated urban areas, where the demand for ecosystem services is the highest, the supply is close to nothing. Consequently, (urban) green infrastructure (UGI) and the ecosystem services it provides, are important to increase the resilience of cities against the impacts of climate change and natural hazards such as droughts and floods. UGI are means to reduce the urban heat island effect, improve limited water retention and infiltration capacity in densely urbanized areas, while at the same time enhancing biodiversity and human wellbeing. The aspect of human wellbeing not only results from healthier living environments, but also from the capacity of urban green to produce greater social capital (Coutts \& Hahn, 2015). The increasing number of cities engaged in international gatherings such as C40 (C40 Cities Climate Leadership Group Inc., 2019), 100 resilient cities (100 Resilient Cities, 2019) and the Covenant of Mayors (Covenant of Mayors for Climate \& Energy, n.d.) are creating momentum to practically invest in GI.

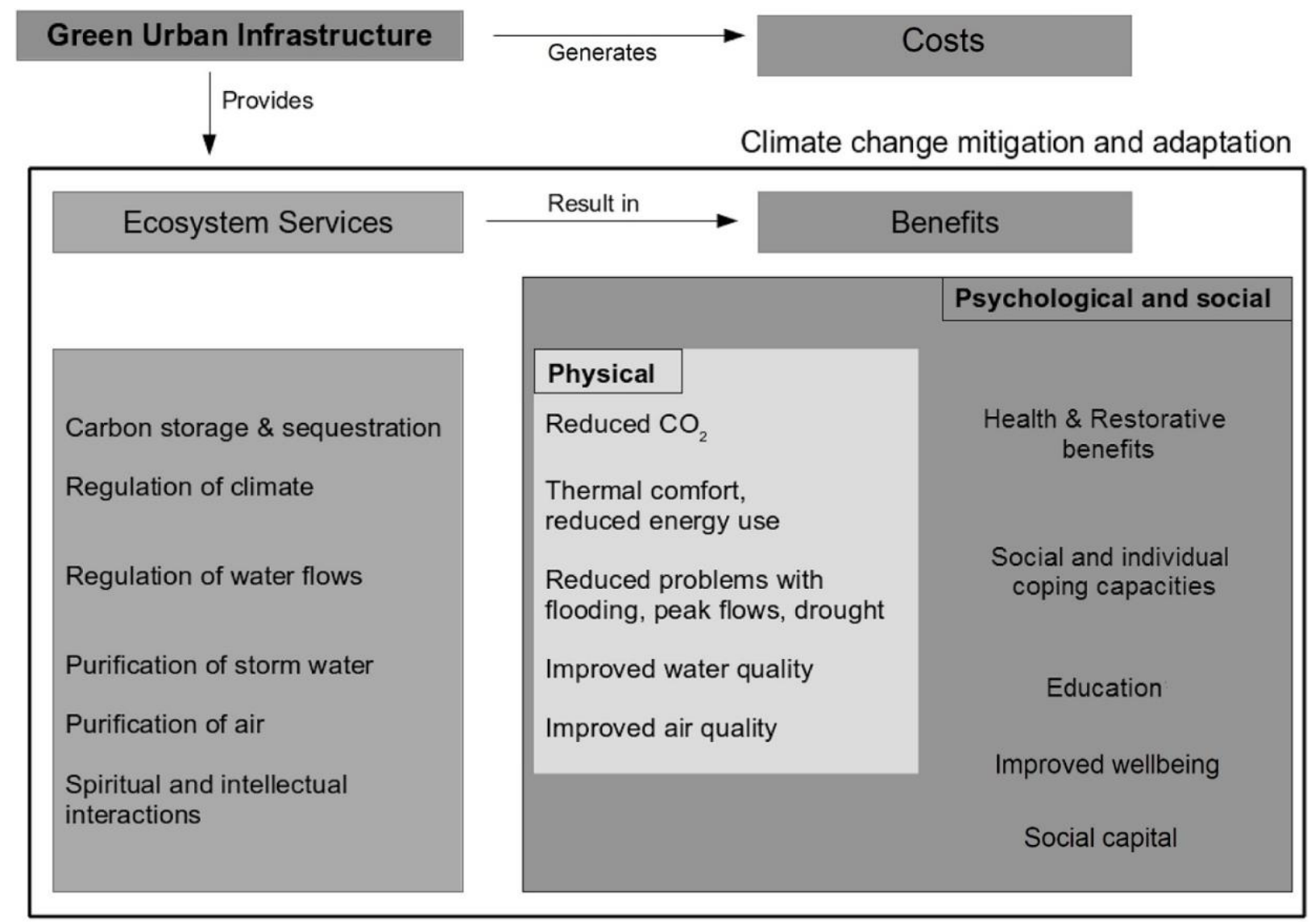

\section{Figure 1: Framework for ecosystem services delivery by urban GI (adapted from Demuzere et al. (2014))}

GI can be defined as the concept of (semi-)natural structures, strategically structured in networks and characterized by their multi-functionality (i.e. multitude of ecosystem services provided)(Benedict \& McMahon, 2012). Examples of urban green infrastructure are permeable vegetated surfaces, green roofs, public parks, green walls, urban forests, green alleys and streets, community gardens and urban wetlands (Gill et al., 2007). Sustainable Drainage systems (SuDS) 
can also be considered an element of GI. UGI is a mean to deliver valuable ecosystem services within the urban environment, figure 1 illustrates how UGI adds value. Consequently, UGI can be described as landscape elements that can provide environmental, economic and social benefits simultaneously. In this paper, the term 'co-benefits' refers to this wide range of benefits that often surpasses the narrower purpose of a UGI element.

The term '(urban) green infrastructure' (UGI) itself is relatively new to academic literature, however the idea is long existing. Despite recent growing academic interest, the implementation of UGI into practice remains slow (Dhakal \& Chevalier, 2017). The reasons for the hampering uptake of UGI are diverse. Where initial GI research was focused on (bio-)physical dimensions, the momentum is starting to shift towards socio-cultural, institutional and political conditions. This led to various studies identifying barriers for GI uptake, a non-exhaustive oversight is provided in table 1 .

Table 1: Overview of current barriers towards GI uptake

\begin{tabular}{|c|c|}
\hline Barriers & Source \\
\hline $\begin{array}{l}\text { Multifunctional GI spans different community agencies and their roles } \\
\text { (e.g. water, transport infrastructure, buildings, ...), uncertainty about the } \\
\text { delivery of benefits from GI, concerns about social acceptance with } \\
\text { citizens. }\end{array}$ & $\begin{array}{l}\text { (Thorne et al., } \\
\text { 2018) }\end{array}$ \\
\hline $\begin{array}{l}\text { Biophysical character of the built environment, planning systems, } \\
\text { institutional frameworks and governance structures, perceptions and } \\
\text { values of urban residents. }\end{array}$ & $\begin{array}{l}\text { (Byrne \& } \\
\text { Jinjun, 2009) }\end{array}$ \\
\hline Path dependency. & $\begin{array}{l}\text { (Matthews et } \\
\text { al., 2015) }\end{array}$ \\
\hline $\begin{array}{l}\text { Uncertainties in cost and performance, lack of engineering standards and } \\
\text { guidelines, fragmented responsibilities, lack of institutional capacity, } \\
\text { lack of legislative mandate, funding constraints, resistance to change. }\end{array}$ & $\begin{array}{l}\text { (Roy et al., } \\
2008 \text { ) }\end{array}$ \\
\hline $\begin{array}{l}\text { Lack of economic argument, roles and responsibilities, municipal } \\
\text { organization, urban densification, legislation, political interest, time and } \\
\text { workload }\end{array}$ & $\begin{array}{l}\text { (Wihlborg et } \\
\text { al., 2019) }\end{array}$ \\
\hline $\begin{array}{l}\text { Reluctance to support novel approaches, lack of knowledge, funding and } \\
\text { costs, ineffective communication, issues with partnerships, maintenance } \\
\text { and adoption, identifying/quantifying/monetizing the multiple benefits, } \\
\text { legislation. }\end{array}$ & $\begin{array}{l}\text { (O’Donnell et } \\
\text { al., 2017) }\end{array}$ \\
\hline
\end{tabular}

'Green infrastructure' implicitly argues for an equal treatment to 'grey infrastructure'. This is illustrated by the European Strategy on Green Infrastructure. In this strategy, the European Commission urges member states to "ensure that the protection, restoration, creation and 
enhancement of green infrastructure becomes an integral part of spatial planning and territorial development whenever it offers a better alternative, or is complementary, to standard grey choices" (European Commission, 2019). In practice, comparing alternatives is often based on their relative costs and benefits. One reason for the limited implementation of green infrastructure is the lack of knowledge on cost, benefits and impact (table 1). Multiple authors stress that the mainstreaming of UGI not only requires evolutions in urban design principles, also urban governance and thus budgeting processes and structures are to be rethought (Andersson et al., 2014; Shackleton et al., 2018). The latter relates to the first barrier depicted in table 1 . Valuation practices at city scale are rare, leading to uncertainty of economic benefit and impact and multidisciplinary performance. Assessing and quantifying the impacts of UGI is essential in composing economic value, since there is often no observable market value. In literature, valuation is often defined in biogeophysical terms, while economic and social valuation is seldom applied (Brink et al., 2016). As it appears, the transition to economic and financial aspects of urban green infrastructure is not well researched. Economic valuation, e.g. a societal cost-benefit analysis are typically done at a larger scale (Millennium Ecosystem Assessment, 2005). There is a need for economic cost to benefit/utility analyses of urban green elements, addressing all its uses and co-benefits (Lee et al., 2015). Methods and tools to economically assess the value of urban green while also bridging to planning, financial and implementation aspects are needed (Wild et al., 2017).

Valuation of investment projects is a key part of the return-on-investment calculations and eventually decision making. In the Millennium Ecosystem Assessment the necessity for economic valuation was intensively argued, because it provides decision makers and the public with numbers that are readily understandable (Carpenter et al., 2006). However, resource constraints (especially in small city governments) led to the latter being skipped far too often. In contrast to grey infrastructure, where added value is much more tangible, local authorities appear to experience green infrastructure investments as non-performant. Because of that, especially smaller cities are not willing to take the 'risk' (Wihlborg et al., 2019). Evidence in Europe states that investments in urban green infrastructure are scarce and limited to individual, small-scale projects, often the result of active citizenship (van der Jagt et al., 2019), on the other hand subsidies provide another incentive to invest in UGI. Typically, if (innovative) investments (e.g. vertical greening) occur, these are mostly limited to larger cities (Pauleit et al., 2018). Subsidies offer concrete opportunities for (smaller) cities to invest in UGI, but are also limited in scale. The lack of economic valuation currently impedes on credible business case development and thus on informed decision-making for local authorities. Notwithstanding the fact that solutions based on GI prove to not only be environmentally and socially desirable, but also economically superior to their grey alternatives in recent studies (Elmqvist et al., 2015). Thus, for green infrastructure to become economically viable, local authorities need to see the economic rewards to fully commit in green infrastructure on a strategic urban management level.

With the strategic and planning concept of urban green infrastructure, the domain of landscape ecology attempts to integrate the ecological network concept within urban environments (Ahern, 2007). To assess the value of UGI, it is necessary to elaborate on elements that determine the ecological and social functions of GI in cities specifically. Firstly, in cities, the consideration of appropriate scales, rooting in hierarchy theory is important and requires a multi-scaled approach 
for assessments (Ahern, 2007). Existing literature on valuation exercises does not incorporate the importance of the relevant spatial scale. Most often, studies opt to assess green infrastructure on a spatial scale of choice. In order for results to be transferable to other cases, the spatial sensitivity of attributes plays an important role, very often overlooked in non-market benefits today (Lizin et al., 2016). Demuzere et al. (2014) argued that defining the scales of benefits is advantageous on different levels (individual and political and administrative decision making). Secondly, UGI and its value is highly dependent on the co-benefits that are generated during the life-span of the GI structure (Hansen et al., 2019). Existing valuation literature mostly offer partial analyses, focusing on single ecosystem services or values (Gómez-Baggethun \& Barton, 2013). Thirdly, natural structures in urban space typically generate urban ecosystem services, which require additional assessment exercises (Bolund \& Hunhammar, 1999).

All the previous strengthens the relevance of an integrative assessment identifying and analyzing the multi-scale co-benefits that are to be gained from UGI projects. For local authorities to compute socio-economic and biophysical value of GI, valuation tools are emerging. These valuation tools have the potential to help local authorities to overcome (some of) the previously mentioned barriers to UGI implementation. The objective of such tools should be to comprehensively assess the multiscale and multi-functional benefits of UGI. Application of valuation tools could save local authorities a considerable amount of resources - which is especially relevant for smaller cities and communities - while still providing scientifically supported evidence that monetarily expresses the added value of an envisioned project (in the assumption that local authorities aim for fully informed decision making). Although these objectives highlight the potential, exploratory research indicated that local authorities are not using such tools.

In scientific research, biophysical properties of GI have been studied extensively, while socioeconomic and political-institutional dimensions are far less subject to thorough analysis (Matthews et al., 2015). In this review paper we combine those previously mentioned dimensions (politicalinstitutional, socio-economic and biophysical) of UGI in an assessment of existing valuation toolkits for UGI. The objective of this research is to explore the readiness and scientific soundness of a selection of GI/ES valuation toolkits. Concretely, we will assess the suitability and functionality of said tools from the perspective of urban planning and urban land management using a set of indicators/criteria. On the other hand, from guided focus groups and published, peerreviewed literature, local authorities' needs and expectations are addressed. This way, we aim at identifying how these tools can be of added value and in which stages of an urban planning process. Finally, this will allow to identify why valuation tools are currently not used by local authorities and how the future development of valuation tools can be improved to become a key component in facilitating informed urban planning for sustainable and resilient cities. This way we aim at contributing to what O'Donnell et al. (2017) formulated as the main strategy for overcoming

existing barriers to GI implementation: "promotion of multifunctional space and identification and assessment of the multiple benefits".

\section{Method}

A three-fold approach was adopted for reviewing potential evaluation toolkits for green infrastructure. In the following, an elaborate explanation of these three stages is provided: selection 
of valuation tools, identification of evaluation criteria and eventually the assessment of valuation tools based on these evaluation criteria.

\subsection{Selection of valuation tools}

For this part of the study, a systematic literature research (Fig. 2) was conducted. Articles published on ISI Web of Science were examined in accordance with the following queries: "Green infrastructure" AND "Tool" OR "Toolkit", "Green infrastructure" AND Valuation. Because absence of the term "green infrastructure" does not necessarily mean that the underlying concept is missing, the queries: "Ecosystem Services" AND Valuation AND ("Tool" OR "Toolkit") were added. To proceed to the next step, only articles mentioning the use of quick assessment methods in their title or abstract were included for the next stage. Thus, the extensive list of 784 articles was reduced to 116 articles that were subjected for further analysis. The latter sample led to the identification of a preliminary selection of 61 toolkits that have been used in literature to quantify, map or model green infrastructure or ecosystem services. Since local authorities are the principle customer for such tools in this assessment and given their resource constraints, it is assumed that only toolkits that are free-to-use are suited for widespread use. The extensive list of 61 toolkits and their respective reasons for exclusion can be found in appendix A.

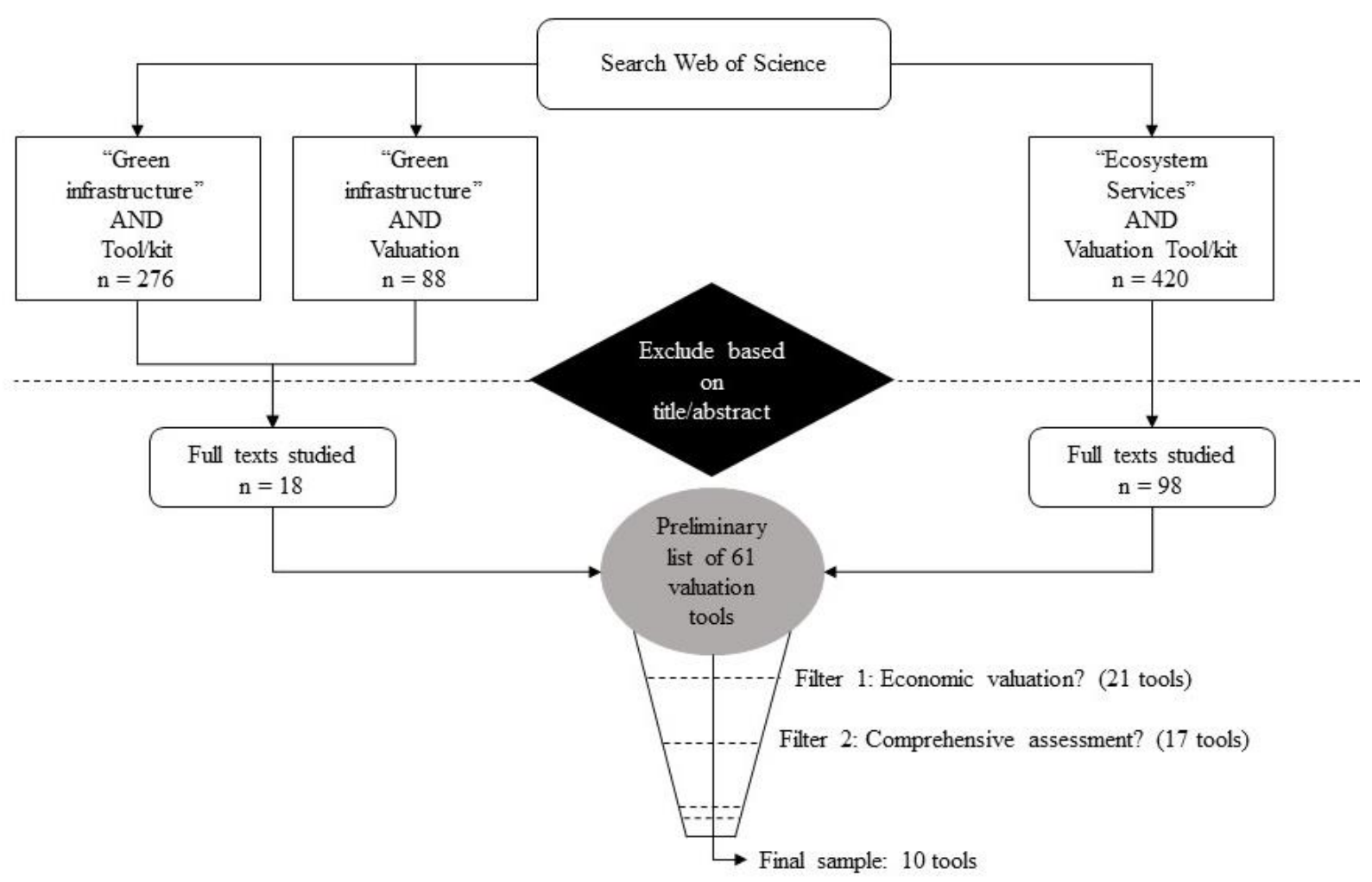

Figure 2: Selection process for evaluation toolkits

After compiling this list from academic literature, all 61 toolkits were individually reviewed through their respective manuals. Given the objective of this comparative study, additional filtering criteria were identified to reach a final sample of toolkits that anticipates application in 
the context of this paper's objectives. The first filter identifies tool(kit)s that attempt or at least objectify a partial monetary valuation of ecosystem services or green infrastructure assets. Thus, the list of tools was reduced from 61 to 22. The second filter covers the nature of the assessment: does the toolkit address the appraisal of one or a few ecosystem services, or does it proposes a comprehensive valuation exercise? Only toolkits ambitioning the latter were considered for further investigation, reducing the list to 17 tools. As GI solutions are characterized by multiple cobenefits, the evaluation of a single goal perspective does not cover the complexity of the netbenefits that are actually generated (Alves et al., 2019). Finally, after excluding valuation toolkits based on several additional determining factors (e.g. toolkits that are out-of-use, predecessors of other toolkits, toolkits that are not publicly available (yet)), the final shortlist was composed of 10 valuation tools designed to value green infrastructure or ecosystem services.

\subsection{Evaluation criteria}

After the identification of the tools that are to be assessed, a list of evaluation criteria was composed. The approach for selection and defining the criteria relies on a two-staged approach. On one hand existing literature contributed to determine current limitations and gaps in both decision making processes and readiness of tools. Based on this first stage, the second stage consisting of guided focus groups - was conducted. Two focus groups took place, consisting of 15 individuals active in different layers of urban planning and decision making in local authorities. The focus groups took place in April and September 2019. These focus groups were organized and led by academics from the institution of the lead author. In practice, they were organized through discussions with local authorities' officers from Belgium, The Netherlands, France and UK. Concretely, the discussions in the first focus group contributed to identifying critical elements in actual decision making and perceptions on the application of quick assessment methods. This input was utilized to create the criteria mentioned below. Moreover, literature review highlighted existing shortcomings and limitations in decision-support tools, that were translated into additional criteria defining the functionality of a tool. The second focus group served to allow participants to validate the criteria as defined. This qualitative research contributes to the applicability of the research in practice, thus realizing impact in actual decision making, advancing towards urban planning and development based on scientifically supported methods. City stakeholders identified additional concerns for toolkits to be widely applicable.

\subsection{Assessment of tools against the criteria}

After composing the list of tools to review and the criteria that could define their applicability, an assessment was made for every tool separately. The assessment of performance on the proposed evaluation criteria was considered through analyzing the user guides, peer-reviewed literature, case studies and eventually through trials of hypothetical scenarios with each of the toolkits. For accessibility reasons, the scoring of a toolkit on all criteria was simplified into a scoring table using a 5-point scale. This 5-point scale ranges from being highly suitable or functional to serve as a decision-support tools within the defined objectives (++) over acceptable (0) to highly unsuitable of dysfunctional to serve as a decision-support tool in the scope of this paper (--). In Appendix B the motivations for assigning different scores are elaborated. 


\section{Results}

Resulting from the literature review, table 2 presents an overview of the shortlist of valuation toolkits. These toolkits are thus all designed to contribute to calculating an economic value of green infrastructure elements and aim at the valuation of a wide range of benefits.

Table 2: Shortlist of valuation toolkits

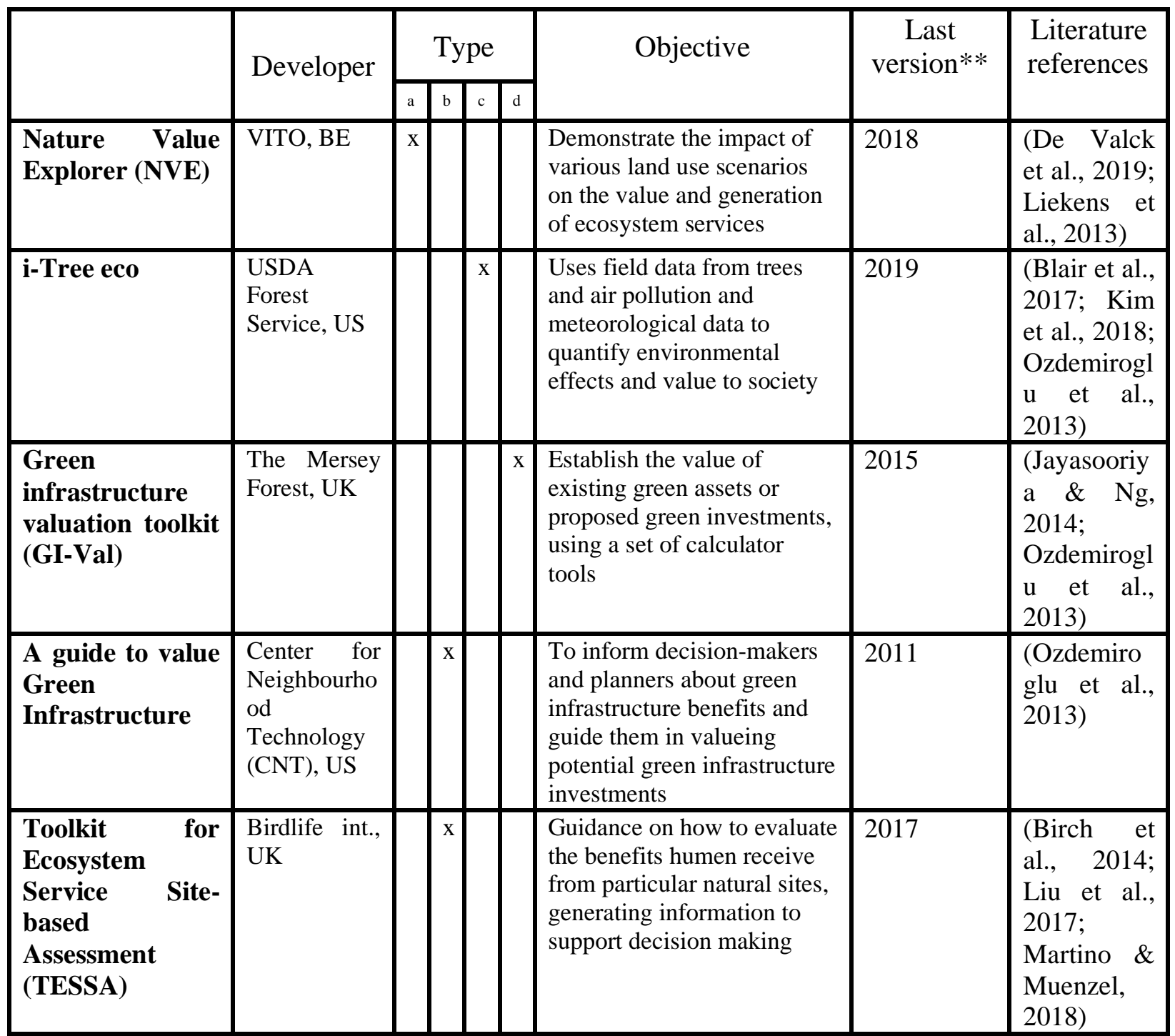




\begin{tabular}{|c|c|c|c|c|c|c|}
\hline $\begin{array}{l}\text { Integrated } \\
\text { Valuation } \\
\text { Ecosytem } \\
\text { Services } \\
\text { Tradeoffs } \\
\text { (InVEST) }\end{array}$ & $\begin{array}{l}\text { Natural } \\
\text { Capital } \\
\text { Project } \\
\text { Stanford } \\
\text { University, } \\
\text { UK }\end{array}$ & $\mathrm{x}$ & & $\begin{array}{l}\text { Facilitate quantification of } \\
\text { tradeoffs associated with } \\
\text { different management } \\
\text { choices and identify areas } \\
\text { where natural capital } \\
\text { investments enhance } \\
\text { development and } \\
\text { conservation }\end{array}$ & 2018 & $\begin{array}{l}\text { (Arcidiacon } \\
\text { o et al., } \\
\text { 2016; Isely } \\
\text { et al., 2010; } \\
\text { Ozdemirogl } \\
\text { u et al., } \\
2013 \text {; von } \\
\text { Essen et al., } \\
2019 \text { ) }\end{array}$ \\
\hline $\begin{array}{l}\text { EcoPLAN } \\
\text { Scenario } \\
\text { Evaluator (SE) }\end{array}$ & $\begin{array}{l}\text { University of } \\
\text { Antwerp, BE }\end{array}$ & $\mathrm{x}$ & & $\begin{array}{l}\text { Evaluate the supply of } \\
\text { ecosystem services to } \\
\text { alternative scenarios in } \\
\text { spatial development projects }\end{array}$ & 2017 & $\begin{array}{l}\text { (Maebe et } \\
\text { al., 2019) }\end{array}$ \\
\hline $\begin{array}{l}\text { Green } \\
\text { Infrastructure } \\
\text { Benefits } \\
\text { Valuation Tool }\end{array}$ & $\begin{array}{l}\text { Earth } \\
\text { Economics, } \\
\text { US }\end{array}$ & & $\mathrm{x}$ & $\begin{array}{l}\text { A quick, screening } \\
\text { assessment of the potential } \\
\text { costs and benefits of } \\
\text { different green infrastructure } \\
\text { investment options }\end{array}$ & 2018 & $\begin{array}{l}\text { (Toledo et } \\
\text { al., 2018)* }\end{array}$ \\
\hline $\begin{array}{lr}\text { Capital } & \begin{array}{r}\text { Asset } \\
\text { Value }\end{array} \\
\text { of } \\
\text { Amenity } & \text { Trees } \\
\text { (CAVAT) } & \end{array}$ & $\begin{array}{l}\text { London Tree } \\
\text { Officers } \\
\text { Association } \\
\text { (LTOA), UK }\end{array}$ & & $\mathrm{x}$ & $\begin{array}{l}\text { A strategic tool and support } \\
\text { for decision making when } \\
\text { the value of the tree stock, or } \\
\text { of a single tree needs to be } \\
\text { expressed in monetary terms }\end{array}$ & 2018 & $\begin{array}{l}\text { (Ozdemiro } \\
\text { glu et al., } \\
2013)\end{array}$ \\
\hline $\begin{array}{l}\text { Benefits } \\
\text { Estimation Tool } \\
\text { (B£ST) }\end{array}$ & $\begin{array}{l}\text { Construction } \\
\text { Industry } \\
\text { Research and } \\
\text { Informaion } \\
\text { Association } \\
\text { (CIRIA), UK }\end{array}$ & & $\mathrm{x}$ & $\begin{array}{l}\text { Evaluate and monetize } \\
\text { economic, social and } \\
\text { environmental benefits of } \\
\text { blue-green infrastructure to } \\
\text { support investment decisions } \\
\text { and identify stakeholders for } \\
\text { potential funding routes. }\end{array}$ & 2019 & $\begin{array}{l}\text { (R. Ashley } \\
\text { et al., 2018; } \\
\text { R. M. } \\
\text { Ashley et } \\
\text { al., 2018) }\end{array}$ \\
\hline
\end{tabular}

a Webtool, b Textual guide, c Computer program, d Spreadsheet

*Case study relies on Ecosystem Services Valuation tool by Earth Economics, exclusively available to members, alternatively the free GI benefits tool from Earth Economics was studied.

** Last version before November 2019

Local authority's officers that took part in the focus group identified several key elements in the process, while academics provided complementary advice to support the scientific credibility of tools. The outcome of the focus groups and literature review is processed in defining 12 criteria that determine the functionality and suitability of decision-support tools in the specific context of urban planning and decision making processes.

\section{Table 3: Criteria for toolkit evaluation}

Type of GI
Different types of GI generate different benefits. Most common types of urban GI: permeable vegetated surfaces, green roofs, public parks, green walls, urban forests, street trees, green alleys and streets, community gardens and urban wetlands. 
Subject of valuation

Time requirement

Expertise requirement

Quantification

Biophysical soundness

Economic soundness

Adaptability

Scalability

Generalizability

Uncertainty
What does the toolkit attempt to valuate? Tools could aim at valuating the range of 'ecosystem services' that are provided by GI, but other tools define their own selection of 'benefits', other tools use even different determinants to compose value. Because toolkits are specifically researched on their capability of being used in urban areas, the inclusion of specific problems that densely populated and concreted places bring forth is important (urban heat islands, pollution, noise, climate resilience, ...)

Time that is required to go through the whole process proposed by a tool.

Are subject-matter experts required throughout different steps of the process of valuation with a certain tool?

Does the tool provide immediate quantification or is the explicit quantification left to the user? Is the quantification focused on biophysical units, monetary outputs or both? Where quantification is complicated, does the toolkit provide qualitative support? LA officers pointed out that economic evidence is currently lacking and strengthens the business case for UGI.

The biophysical drivers that co-define the added economic, environmental and social value need to be measured and assessed accurately to provide reliable input. The methods that are used to biophysically express and predict the impacts of certain types of green infrastructure need to comply with academic standards. Moreover, including data on city-specific ecosystem services is highly relevant (e.g. stormwater run-off, pollution reduction, urban heat island reduction, etc.).

To be treated on the same level as grey infrastructure, green infrastructure needs clear ways of expressing the total economic value. Because of the multi-functional nature of GI, toolkits apply different valuation techniques to monetize the stream of benefits. Critically assessing these techniques and the assumptions made, while using recent peer-reviewed literature as a benchmark will improve the accuracy and replicability of valuation exercises. Except for valuation techniques, it is also important to avoid double counting and thus overstating economic value. Specifically with respect to the urban context, public decision makers are interested in the beneficiaries of these revenue streams, toolkits that would include these distinctions are preferred.

Can a toolkit be tailored to local context? Can calculation mechanisms be altered, or just input data?

Toolkits can be developed to be applied from landscape to parcel scale. LA's emphasize that UGI investments mostly exist of retrofitting, where the size of a project can vary from a single tree up to a wide urban park. Moreover, academics concluded that capturing the key 'network' aspect of GI requires flexibility in scale from a tool.

Ideally, a toolkit would be applicable across different socioeconomic, environmental and geographical circumstances. Many tools are bound to specific regions, which reduces the possibility of transferring the application to other areas. On the other hand, detailed region-specific properties can result in more accurate local estimations.

Given that infrastructure costs and benefits within urban environments are highly sensitive, further the generation of co-benefits is also volatile. Tools 
that include sensitivity into modelling and estimating are preferred. Tools that just provide point values lead to distrust.

Scenario analysis To be applied as a strategic decision-support toolkit, a toolkit must be able to calculate different spatial planning scenarios and compare this to the current state of the urban landscape. This way, one can straightforwardly observe how projects affect the stock of ecosystem services. It also offers the opportunity to improve participatory decision making with local stakeholders.

After composing the list of tools to review and the criteria that could define their applicability, an assessment was made for every tool separately. While table 4 introduces a summary of the performance on the most important evaluating features for every criterion, the full qualitative assessment can be found in Appendix B. Table 5 was designed to provide an intuitive overview, facilitating to draw conclusions from the qualitative assessment. 
Table 4: Summarized assessment of valuation tools

\begin{tabular}{|c|c|c|c|c|c|c|c|c|c|c|c|c|c|c|c|c|c|c|}
\hline & GIa & $\mathbf{S V}_{\mathbf{b}}$ & TRe & $\mathbf{E R}_{\mathbf{d}}$ & $\mathbf{Q}_{\mathbf{e}}$ & $\mathbf{B S}_{\mathbf{f}}$ & & & & ESn & & & $\mathbf{A i}$ & $\mathbf{S}_{\mathbf{j}}$ & $\mathbf{G k}_{\mathbf{k}}$ & $\mathbf{U}_{\mathbf{l}}$ & & SAm \\
\hline & & & & & & $\mathbf{A R}$ & $\mathbf{T}$ & $\mathbf{F b}$ & $\mathbf{U C}$ & $\mathbf{A R}$ & DC & EAh & & & & $\mathbf{R}$ & QRA & \\
\hline NVE & $\mathbf{x}$ & ES & 2 & $\mathbf{N E}$ & Both & $\mathbf{x}$ & $\mathbf{x}$ & & $\mathbf{x}$ & $\mathbf{x}$ & & YB & Id & $\mathbf{x}$ & SE & $\mathbf{x}$ & & $\mathbf{x}$ \\
\hline i-Tree eco & & ES & 4 & $\mathbf{M}$ & Both & & $\mathbf{x}$ & & $\mathbf{x}$ & $\mathbf{x}$ & & Und. & Id & $\mathbf{x}$ & BT & & & \\
\hline Gi-Val & $\mathbf{x}$ & B & 2 & $\mathbf{C}$ & Mon & & & & $\mathbf{x}$ & & $\mathbf{x}$ & TEV/NPV & Id & $\mathbf{x}$ & BT & & & $\mathbf{x}$ \\
\hline CNT & $\mathbf{x}$ & B & 2 & $\mathbf{C}$ & NQ & $\mathbf{x}$ & & & $\mathbf{x}$ & $\mathbf{x}$ & $\mathbf{x}$ & YB & Id,Meth,Sub & & BT & & & $\mathbf{x}$ \\
\hline TESSA & & ES & 5 & C & NQ & $\mathbf{x}$ & & & & $\mathbf{x}$ & & BB & Id,Meth,Sub & & BT & & & \\
\hline InVEST & & ES & 4 & $\mathbf{P}$ & Bio & $\mathbf{x}$ & & & & $\mathbf{x}$ & & BB & Id & & SE & & & $\mathbf{x}$ \\
\hline EcoPLAN-SE & & ES & 3 & $\mathbf{P}$ & Both & $\mathbf{x}$ & & $\mathbf{x}$ & $\mathbf{x}$ & $\mathbf{x}$ & & YB & Id & $\mathbf{x}$ & NG & & & $\mathbf{x}$ \\
\hline GI Benefits valuation tool & $\mathbf{x}$ & B & 1 & $\mathbf{N E}$ & Mon & $\mathbf{x}$ & $\mathbf{x}$ & & & $\mathbf{x}$ & & NPV, IRR, BCR & Id & & BT & & & $\mathbf{x}$ \\
\hline CAVAT & & $\mathbf{O}$ & 4 & $\mathbf{M}$ & Mon & & $\mathbf{x}$ & & $\mathbf{x}$ & & & TEV & Id & $\mathbf{x}$ & BT & & & \\
\hline B£ST & $\mathbf{x}$ & B & 3 & NE & Both & $\mathbf{x}$ & $\mathbf{x}$ & & & $\mathbf{x}$ & $\mathbf{x}$ & TEV, NPV, BCR & Id,Meth,Sub & $\mathbf{x}$ & BT & $\mathbf{x}$ & $\mathbf{x}$ & $\mathbf{x}$ \\
\hline
\end{tabular}

a GI = Green infrastructure.

$\mathrm{b} \mathrm{SV}=$ Subject of valuation. $\mathrm{ES}=$ ecosystem services; $\mathrm{B}=$ benefit categories; $\mathrm{O}=$ Other.

c TR $=$ Time requirement. Varying from 1 (quick assessment) to 5 (extensive time requirement)

d ER = Expertise requirement. $\mathrm{C}=$ expertise needed for calculations; $\mathrm{P}=$ expertise needed for programming; $\mathrm{M}=$ expertise needed for measurements; $\mathrm{NE}=$ no need for specific expertise

e $Q$ = Quantification. Bio = Output in biophysical units; Mon = Output in monetary units; Both = Output in Bio and Mon units; NQ = No explicit quantification

$\mathrm{f} \mathrm{BS}=$ Biophysical soundness. $\mathrm{AR}=$ Academic referencing; $\mathrm{T}=$ Time horizon of benefits; Fb = Feedback between ecosystem services/benefits; UC $=$ Urban character

$\mathrm{g}$ ESn = Economic soundness. $\mathrm{AR}=$ Academic referencing; $\mathrm{DC}=$ Acknowledges double counting; $\mathrm{EA}=$ Economic analysis

h $\mathrm{YB}=$ yearly benefits, $\mathrm{TEV}=$ total economic value; $\mathrm{NPV}=$ net present value; $\mathrm{BB}=$ benefits compared to baseline scenario; IRR $=$ internal rate of return; $\mathrm{BCR}=$ benefit cost ratio;

Und. = undefined

i A = Adaptability. Id = Input data for calculations adaptable; Meth = Methods to valuate adaptable; Sub = Subjects of valuation adaptable; NA = Not adaptable.

j $\mathrm{S}=$ Scalability - transferable over different spatial scales.

k $\mathrm{G}=$ Generalizability. $\mathrm{SE}=$ need spatially explicit data; $\mathrm{BT}=$ With benefit transfer methods; NG = Not generalizable.

$1 \mathrm{U}=$ Uncertainties. $\mathrm{R}=$ Ranges for value; $\mathrm{QRA}=$ Quantitative risk analysis.

$\mathrm{m}$ SA $=$ Scenario analysis 
Table 5: Overview of toolkit performance

\begin{tabular}{|c|c|c|c|c|c|c|c|c|c|c|c|c|}
\hline & 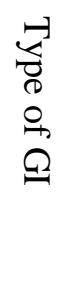 & 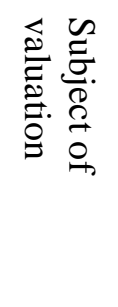 & 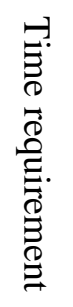 & 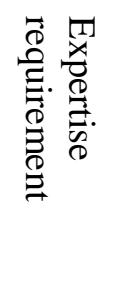 & 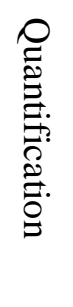 & 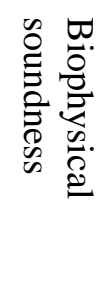 & 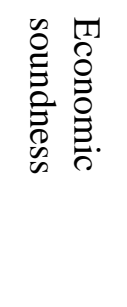 & 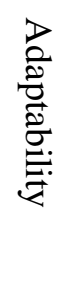 & 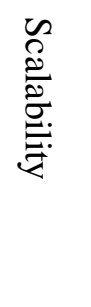 & 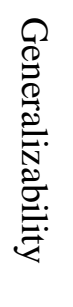 & 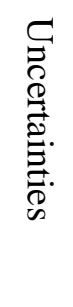 & 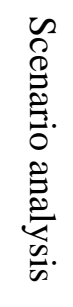 \\
\hline NVE & ++ & ++ & + & ++ & ++ & + & 0 & 0 & ++ & + & 0 & ++ \\
\hline i-Tree eco & -- & ++ & - & -- & + & - & 0 & 0 & ++ & - & -- & -- \\
\hline GI-Val & ++ & -- & + & 0 & 0 & - & - & 0 & ++ & - & -- & ++ \\
\hline CNT & ++ & -- & + & 0 & -- & + & + & + & 0 & - & -- & ++ \\
\hline TESSA & -- & ++ & -- & 0 & -- & 0 & + & + & 0 & - & - & ++ \\
\hline InVEST & -- & ++ & - & -- & - & 0 & 0 & 0 & -- & + & 0 & ++ \\
\hline EcoPLAN & -- & ++ & -- & -- & ++ & + & 0 & 0 & ++ & -- & -- & ++ \\
\hline GI benefits tool & ++ & -- & ++ & ++ & 0 & - & + & 0 & 0 & - & -- & ++ \\
\hline CAVAT & -- & -- & - & -- & 0 & -- & -- & 0 & ++ & + & -- & -- \\
\hline $\mathrm{BEST}$ & ++ & -- & 0 & ++ & 0 & + & ++ & + & ++ & - & + & ++ \\
\hline
\end{tabular}




\section{Discussion}

The specific objective of this literature review is to assess the possibility for widespread use in urban areas. Since urban areas bring forth specific challenges, it is necessary for a toolkit to take account of this city-specific context in order to be recommendable. Apart from this, the target customers that are considered in this review - local authorities - introduce additional requirements for the applicability of such toolkits. As can be concluded from reviewing the existing literature, the amount of green infrastructure/ecosystem services toolkits including economic valuation practices is very limited, especially when it is compared with the amount of biophysical and hydrological modelling tools. However, it must be stressed that the shortlisted tools are the result of literature reviews based on specific keywords, as explained in the method. Still, where many tools facilitate modelling and planning (urban) environments and their biophysical features, the lack of economic values stipulates a current gap in research. Nevertheless, aside from the usefulness of biophysical assessments, local authorities' decision makers and planners indicated that economic value is often required in order to convince relevant stakeholders, and thus a key component towards mainstreaming investments in urban green infrastructure. The results and discussion as they are presented, are most relevant to urban contexts in developed countries. Because the nature of green infrastructure investments in developed countries relies mostly on retrofitted solutions, this has been a key point of view in conducting the assessments of the valuation tools.

Since the assessment is based on the definition of 12 criteria, sometimes further simplified in indicative subcriteria, it must be stressed that the results as they are shown can be subject for discussion. It is for example self-evident that the assessment of biophysical soundness exceeds the limited selection of subcriteria as they are shown in table 3 and table 4 . However, in order to support the interpretability and harmonize the objectives of this review with findings from literature, such tables provide a valuable oversight. Moreover, the criteria as they are defined, can not be seen as independent parts of a comprehensive assessment. Criteria are often interdependent, given that handling a certain toolkit requires a lot of expertise, this will also result in higher time requirement for example.

These interdependencies are a key element in discussing GI/ES valuation toolkits. The interdependence and interference of ecosystem services, complicates accurately capturing the economic value, since it introduces the risk for double counting. Only three toolkits (Gi-Val, CNT and B£ST) provide users specific guidance in coping with this issue. InVEST on the other hand generates source for double counting in providing a multitude of different models, without consideration of interdependencies. Other toolkits often indicate to provide conservative estimates, or omit the concept of double counting in general. The source for this lack of consideration of double counting on the economic side, may reflect the lack of considering feedback loops in ecosystem services production from the biophysical side. A clear oversight of the linkages between the ecosystem services that green infrastructure generates, as well as an oversight of the relationships between the social and ecological systems could benefit the reliability in economically assessing the value. This also relates to self-defined benefit categories as observed 
with Gi-VAL, CNT, GI Benefits Tool and B£ST. Deferring from published categorizations provides additional source for double counting.

Analyzing the first two columns in table 4 sets another concern for using current toolkits. Where half of the toolkits are specifically designed to facilitate green infrastructure valuations, only one of these utilizes the ecosystem services approach to conduct the valuation exercise. Sticking to the ecosystem services approach is valuable, since the concept is generally accepted and research in this field is improving rapidly. Gi-Val, CNT, GI Benefits tool and B£ST all apply self-defined benefit categories. From literature research it shows that these roughly defined categories provide additional source for double counting. This does not imply that the ecosystem services approach is free of double counting, through the interrelations of ES, complexity and non-linearity is inherent (Bennett et al., 2009; Raudsepp-Hearne et al., 2010). This results in temporal and spatial trade-offs (Rodríguez et al., 2006) and synergies (Bennett et al., 2009) that ought to be identified (Rodríguez et al., 2006), ideally toolkits are capable of this. Another argument to opt for the valuation of ecosystem services is its capability to conduct targeted studies. Furthermore, since most of the toolkits are a 'living mechanism' and subject to regular improvements, leaving the emerging field of ecosystem services is not advisable.

Toolkits that mention adaptations for densely populated areas and explicitly elaborate on urban issues are preferred. On this matter, there is extensive room for improvement. From the quantitative toolkits only Nature Value Explorer, i-Tree Eco and EcoPLAN-SE consider adaptations for the specificities of urban areas and are thus desirable within the scope of this review. However, since the urban environment often requires creative use of public space, inclusion of as many green infrastructure elements (eg. green walls, green roofs) significantly contributes to the applicability. On this latter criterion, i-Tree eco is less convenient since it only evaluates urban trees/forests. EcoPLAN-SE on the other hand doesn't provide built-in features for green infrastructure types.

Regarding the time and expertise requirement, important trade-offs need to be made. Toolkits that can be performed fast and without experts, typically make use of default values. While default values are convenient - especially in initial planning phases - one must not forget that these can only provide initial indicative values in a project development process. In the urban planning and developing process, it is required that these valuations are performed by competent and critical people that understand the underlying valuation methods and the consequences of using default values and benefit transfer systems. After all, benefit transfer is an inevitable and precious technique for data/resource scarce environments, but one must account for the correspondence issues that will arise if this type of valuation is not applied with care (Plummer, 2009). Moreover, several tools that were studied (eg. Gi-VAL, NVE, ...) claim that further research is required on the impact of green infrastructure installments and the contributions of urban ecosystems. Given the current research gap, this underlines the fact that in applying benefit transfers one should be conscious of generalization errors. It was found that toolkits relying on GIS provide a stronger scientific basis, while shortening the time requirement for data collection. Evidently, utilizing geographically specific data improves the performance of quantification without requiring the user to provide many additional measurements. Moreover, including GIS analyses aids to identify areas 
where GI intervention is relevant, by layering data on different ecological functions (Hansen et al., 2019). Narrowing down the selection based on GIS, only Nature Value Explorer, EcoPLAN-SE and InVEST are left. The CAVAT tool on the other side is hardly applicable in the urban planning context that is considered in this review, especially if ex-ante valuation would be considered.

EcoPLAN-SE indicates that the methods have been designed for the Flanders region specifically and InVEST does not provide economic valuation for many ecosystem services. Thus, to perform a general basic valuation exercise, Nature Value Explorer appears to be the most reliable toolkit, for local authorities in Flanders (Belgium). Theoretically, this toolkit could be generalizable too, if GIS data are provided by the user. This does however not imply that such generalized experiments would induce reliable results. Since most of the calculations are made with numbers specific to the Flanders region, spatially explicit data need to be provided to support accuracy. The limited suitability of generalizability limits the ability for widespread use. The values provided give an indication of the ecosystem services that are relevant to consider in making a GI investment. However, the manual also indicates that a few topics require more elaborate methods and expert analysis to generate accurate results. It is also noticed that Nature Value Explorer does not cover all ecosystem services. Especially in terms of cultural ecosystem services - although valuation methods are sometimes subject of debate - the model can still use improvements. The biggest shortcoming for Nature Value Explorer is the lack of explicit monetization of temperature regulating services. Studies of energy savings resulting from green roofs and green walls indicate that monetary benefits from reduced energy demands comprise approximately $50 \%$ of the total monetary benefits (Foster et al., 2011). A single $8 \mathrm{~m}$ tall tree could reduce annual residential heating and cooling costs with 8-12\% (McPherson \& Rowntree, 1993). Although these numbers are highly sensitive to the climate zone that is considered, they demonstrate the concern to consider the monetization of this ecosystem service when it is aimed to perform a comprehensive monetary valuation of an urban green infrastructure installment.

A critical shortcoming that vastly influences the outcome of UGI is the notion of life-span assessments. In comparing grey and green infrastructure, it is noticeable that the advantage of GI clearly lies in the generation of multiple co-benefits. These co-benefits should be assessed on the life-span of GI structures, which extends beyond current valuation practices for all toolkits. Moreover, social and environmental gains - although often hard to monetize - are likely to bring forth substantial benefits, especially when considering the amount of beneficiaries in urbanized environments, which contribute to justifying UGI investments. In this regard, significant shortterm social and environmental benefits could justify a potential long-term return on investment. Regarding scalability, most toolkits allow valuation of projects across varying landscape scales. Additionally, toolkits might benefit from including a spatial-temporal scale for different processes/ecosystem services in order to support appropriate assessment and decision making in the urban context, similar to the approach taken by Papadimitriou and Mairota (1996) for rural policy planning.

Another critique on the actual valuation tools is the lack of consideration of the cost-side. Similar to the net present value (NPV) in grey infrastructure, the costs need to be introduced to make a realistic argument for green infrastructure. In this regard, three essential parts implicit to GI 
investments are to be taken into account: investment costs, maintenance costs and ecosystem disservices (see table 1: current barriers to GI adoption). Only B£ST really elaborates on developing the economic case for green infrastructure. In the field of urban planning and management, terms as 'return on investment' are critical in decision-making. A guided example of cost calculation, depreciation and discounting regarding urban green infrastructure can aid local authorities in developing a credible business case, equivalent to what is common practice in grey infrastructure investments, the maintenance costs need to be included as well. Moreover, it should be taken into account that urban greening not only features ecosystem services, but also generate ecosystem disservices. The discussion on ecosystem disservices is emerging and especially important in urban greening management contexts (Lyytimäki \& Sipilä, 2009). Especially in densely populated cities, some ecosystem disservices may introduce substantial value deductions through the amount of beneficiaries (e.g. allergies), thus require . At the moment it is noticed the toolkits in this review either focus on biophysical assessments and provide quick economic guidance on the side, or either focus on monetizing ecosystem services and neglect the biophysical foundation. Ideally, applying a toolkit would provide local authorities with the biophysical, economic and social arguments that support the business case for urban green infrastructure. This includes scientifically sound valuations of biophysical, economic and social impacts, and also at least a qualitative overview of 'invaluable' ecosystem services. Furthermore, the (limited) cost side of valuation toolkits illustrates a gap in actual research. Where the benefit side is often scientifically motivated by peer-reviewed default value data, no such practices are common in cost calculation. In order to make credible business cases for green infrastructure project development, both benefit and costs are expected to be scientifically motivated. On this matter, unit values on infrastructure and maintenance costs could improve the performance and field of application of valuation toolkits significantly.

To support realistic business cases, valuation toolkits are required to spend considerable more amount of caution on the uncertainties that are faced. By only providing point values, toolkits give the impression that we can perfectly predict future value. In what is discussed before, many elements that introduce uncertainty can be identified. First the interdependencies of ecosystem services, which have been explained to cause double counting. Secondly, the wide array of valuation techniques that are used to value ecosystem services and include limitations (e.g. travel cost method or contingent valuation studies). Thirdly, it was observed that executing valuations with the toolkits in other geographical areas entails the application of benefit transfer methods. Given the uncertainty that these practices generate for a valuation exercise, it is critical to have insight into the risks.

From another point of view, focus groups with officers involved in the urban planning and decision making process highlighted shortcomings from their side. Where valuation toolkits put effort into scientifically supporting the case for GI investments, this scientific approach is less mainstream within local authorities, especially when it comes to the added value of urban green. Often, when offering green investments there is a sense of 'false satisfaction'. This perception of 'green is good enough' limits the potential added value of such investments, and this is a fundamental breaking point with grey infrastructure decision making processes and structure. In order to make public space management more evidence-based, guides for valuation of green infrastructure could be of 
value (CNT, TESSA). As stated in Matthews et al. (2015) by a senior executive local government policy planner and urban designer: "demonstrating the multiple benefits of green infrastructure will build the support with developers and the public that is needed". Whilst TESSA is not advised to put numbers on GI projects and is not adapted for urban assessments, it introduces an easily accessible and step-by-step elaboration on scientific evidence of the whole process in assessing a GI investment. Moreover, it is useful in conducting at least qualitative assessments that precede translation to monetary values, and as a mean of capacity building with non-experts, especially in the near future, when they plan to release an urban guide.

In consulting with local authorities and conducting literature reviews, it was found that some toolkits are developing updated versions specific for urban contexts (e.g. InVEST, Nature Value Explorer, ECOPLAN) and other toolkits are under development (ARIES, Greenkeeper). The advancement towards tools specifically designed to serve as urban decision-support tools can only be supported. Both ARIES and Greenkeeper have indicated to release publicly available prototypes by the end of 2020, and both will use big data for ecosystem services valuation. Greenkeeper defines the use of big data as adopting: "a researched and layered range of data sources, combining freely available data sources with specifically commissioned smart data (e.g. mobile phone location data) and emerging research findings" (Greenkeeper, 2019). This transition towards big data applications in ecosystem services valuation may help to reduce the uncertainties and time/expertise requirements that were identified in this research. Importantly, these toolkits should be subject to a constant review and update. Current toolkits are often the result of research projects that phase out once the project period terminates.

Further, it is critical that these toolkits are developed in cooperation with their target customers (local authorities). All the previous highlighted factors that hamper the uptake of the decisionsupport tools in practice. Aligning the needs of local authorities with the scientific methods to support informed decision making should be the fundamental idea to improve quick assessment toolkits for UGI. This must be an important objective for future green infrastructure research in general: bridging theoretical, scientific insight with practical urban planners, developers and decision makers.

\section{Conclusion}

In the rising urgency of building resilient and healthy urban environments, one of the main obstructions in making green infrastructure investments, is the lack of acknowledgement of the added value such investments generate. Since local authorities are restricted in resources, committing to time and money intensive valuation processes is not feasible on a project-scale. In an attempt to overcome this problem, valuation toolkits have emerged to provide the instruments for developers to conduct such valuation exercises. Nevertheless, it is noticed that such toolkits are not employed today, resulting in slow installment of urban green infrastructure. In consequence, local authorities have no sense of value and are thus discouraged to make such investments and instead rely on subsidies.

This literature review has the objective to explore which valuation toolkits are available for local authorities at the moment to value urban green infrastructure investments, as well as identify the 
shortcomings and limitations of these tools. We can conclude that while some valuation toolkits operate from a strong scientific base, most of these toolkits are more concerned about simplicity. Because of this, tools are currently only fit for use in the early project development stages to get a sense of the ecosystem services that would be generated from the project. Ideally, the tools are the first step, followed by an in-depth and spatially explicit assessment of the most important ecosystem services. In the future, the development of toolkits that make use of big data could possibly contribute to overcome this requirement. However, this also implies the need for further research into current data gaps on urban ecosystems, urban green infrastructure and their ecological/socio-economic impacts.

Importantly, it must be stressed that this review does not attempt to undermine the biological and ecological importance of nature by reducing it to monetary values. Since it is objectified to support credible business cases for urban green infrastructure that can compete with grey infrastructure in a competitive context of urban space, monetary values are an inevitable instrument towards mainstreaming such investments. Having these numbers, endorsed by qualitative input on the ecological functions and processes, must be the main objective for profound assessments.

The threats of urbanization often push back the quantity of urban green, hence the need for optimal quality. To benefit from locally optimal solutions, tools should be applicable at project-scale to landscape-scale and in different geographic and socio-economic environments. Because of this, we advise future GI tools to be GIS-based and open-source, so that local authorities can input their proper GIS-data and adapt methods if necessary. With the objective of building the business case for GI, future tools should pay additional attention to life-span assessments of UGI structures, the cost-side and indicators of economic performance. To make the tools more realistic, a quantitative risk analysis should be included. In order to provide local authorities with the basis for business cases that objectify equal treatment with 'grey infrastructure', these are the minimum requirements. Ideally, tools would even be able to distinguish between the beneficiaries of the ecosystem services that are generated through urban green, which could mean a next step towards sustainable financing of such projects. Finally, another critical outcome of this review is the tradeoffs that are to make by valuation toolkits. Since the evaluative criteria are often correlated, valuation toolkits have to find balances (eg. simplicity - scientific soundness). In our opinion and relevant for toolkit developers - this requires valuation toolkit developers to utilize participative approaches to design such instruments. In consulting local authorities and identifying their specific hurdles and requirements, scientists can compose frameworks that are tailor-made and readily usable to be put into practice and contribute to the attractive, healthy and climate resilient urban landscapes of tomorrow.

Further research should aim at filling the gaps that are demonstrated in this literature review. By acknowledging the specific requirements and insights and the shortcomings of actual valuation toolkits, it should be objectified to compile advanced valuation methods with a thorough scientific base. Eventually, studying the total economic value and its beneficiaries, appropriate finance methods should be introduced. Since it is observed that valuation toolkits are in constant development, we are convinced that the insights from jointly (academic and local authorities) delivering these cases will provide the opportunity for current toolkits to be validated, 
appropriately updated, as well as for toolkits that are under development to add significantly to the actual state-of-the-art.

\section{Acknowledgement}

Nature Smart Cities across the 2 Seas is an Interreg 2 Seas co-funded project to the value of $€ 6,380,472$. It consists of a total of 11 Partners from 4 EU Member States, who will work together to develop a business model that local authorities can use to justify the use of 'city finance' to fund their urban greening programmes. This project has received funding from the Interreg 2 Seas programme 2014-2020 co-funded by the European Regional Development Fund under subsidy contract No 2S05-048.

\section{References}

100 Resilient Cities. (2019). 100 Resilient Cities, Pioneered by the Rockefeller Foundation. Retrieved from http://www.100resilientcities.org/

Ahern, J. (2007). Green infrastructure for cities: the spatial dimension. In. Paper presented at the Cities of the future: towards integrated sustainable water and landscape management. IWA Publishing.

Alves, A., Gersonius, B., Kapelan, Z., Vojinovic, Z., \& Sanchez, A. (2019). Assessing the CoBenefits of green-blue-grey infrastructure for sustainable urban flood risk management. Journal of Environmental Management, 239, 244-254. doi:https://doi.org/10.1016/j.jenvman.2019.03.036

Andersson, E., Barthel, S., Borgström, S., Colding, J., Elmqvist, T., Folke, C., \& Gren, Å. (2014). Reconnecting Cities to the Biosphere: Stewardship of Green Infrastructure and Urban Ecosystem Services. AMBIO, 43(4), 445-453. doi:10.1007/s13280-014-0506-y

Arcidiacono, A., Ronchi, S., \& Salata, S. (2016). Managing Multiple Ecosystem Services for Landscape Conservation: A Green Infrastructure in Lombardy Region. Procedia Engineering, 161, 2297-2303. doi:https://doi.org/10.1016/j.proeng.2016.08.831

Ashley, R., Gersonius, B., Digman, C., Horton, B., Smith, B., \& Shaffer, P. (2018). Including uncertainty in valuing blue and green infrastructure for stormwater management. Ecosystem Services, 33, 237-246. doi:https://doi.org/10.1016/j.ecoser.2018.08.011

Ashley, R. M., Gersonius, B., Digman, C., Horton, B., Bacchin, T., Smith, B., . . Baylis, A. (2018). Demonstrating and Monetizing the Multiple Benefits from Using SuDS. Journal of Sustainable Water in the Built Environment, 4(2), 05017008. doi:10.1061/JSWBAY.0000848

Benedict, M. A., \& McMahon, E. T. (2012). Green infrastructure: linking landscapes and communities: Island press.

Bennett, E. M., Peterson, G. D., \& Gordon, L. J. (2009). Understanding relationships among multiple ecosystem services. Ecology letters, 12(12), 1394-1404.

Birch, J. C., Thapa, I., Balmford, A., Bradbury, R. B., Brown, C., Butchart, S. H. M., . . . Thomas, D. H. L. (2014). What benefits do community forests provide, and to whom? A rapid assessment of ecosystem services from a Himalayan forest, Nepal. Ecosystem Services, 8, 118-127. doi:https://doi.org/10.1016/j.ecoser.2014.03.005 
Blair, J., Roldan, C., Ghosh, S., \& Yung, S.-H. (2017). Greening Rail Infrastructure for Carbon Benefits. Procedia Engineering, 180, 1716-1724. doi:https://doi.org/10.1016/j.proeng.2017.04.334

Bolund, P., \& Hunhammar, S. (1999). Ecosystem services in urban areas. Ecological Economics, 29(2), 293-301. doi:https://doi.org/10.1016/S0921-8009(99)00013-0

Brink, E., Aalders, T., Adam, D., Feller, R., Henselek, Y., Hoffmann, A., .. . Wamsler, C. (2016). Cascades of green: A review of ecosystem-based adaptation in urban areas. Global Environmental Change-Human and Policy Dimensions, 36, 111-123. doi:10.1016/j.gloenvcha.2015.11.003

Byrne, J., \& Jinjun, Y. (2009). Can urban greenspace combat climate change? Towards a subtropical cities research agenda. Australian Planner, 46(4), 36-43.

C40 Cities Climate Leadership Group Inc. (2019). C40. Retrieved from https://www.c40.org/

Carpenter, S. R., DeFries, R., Dietz, T., Mooney, H. A., Polasky, S., Reid, W. V., \& Scholes, R. J. (2006). Millennium ecosystem assessment: research needs. In: American Association for the Advancement of Science.

Coutts, C., \& Hahn, M. (2015). Green Infrastructure, Ecosystem Services, and Human Health. International journal of environmental research and public health, 12(8), 9768-9798. doi:10.3390/ijerph120809768

Covenant of Mayors for Climate \& Energy. (n.d.). Covenant of Mayors.

De Valck, J., Beames, A., Liekens, I., Bettens, M., Seuntjens, P., \& Broekx, S. (2019). Valuing urban ecosystem services in sustainable brownfield redevelopment. Ecosystem Services, 35, 139-149. doi:https://doi.org/10.1016/j.ecoser.2018.12.006

Demuzere, M., Orru, K., Heidrich, O., Olazabal, E., Geneletti, D., Orru, H., . . Faehnle, M. (2014). Mitigating and adapting to climate change: Multi-functional and multi-scale assessment of green urban infrastructure. Journal of Environmental Management, 146, 107-115. doi:10.1016/j.jenvman.2014.07.025

Dhakal, K. P., \& Chevalier, L. R. (2017). Managing urban stormwater for urban sustainability: Barriers and policy solutions for green infrastructure application. Journal of Environmental Management, 203, 171-181. doi:10.1016/j.jenvman.2017.07.065

Elmqvist, T., Setälä, H., Handel, S. N., van der Ploeg, S., Aronson, J., Blignaut, J. N., . . . de Groot, R. (2015). Benefits of restoring ecosystem services in urban areas. Current Opinion in Environmental Sustainability, 14, 101-108. doi:https://doi.org/10.1016/j.cosust.2015.05.001

European Commission. (2019). Ecosystem services and Green Infrastructure. Retrieved from https://ec.europa.eu/environment/nature/ecosystems/index_en.htm

Foster, J., Lowe, A., \& Winkelman, S. (2011). The value of green infrastructure for urban climate adaptation. Center for Clean Air Policy, 750(1), 1-52.

Gill, S. E., Handley, J. F., Ennos, A. R., \& Pauleit, S. (2007). Adapting cities for climate change: the role of the green infrastructure. Built environment, 33(1), 115-133.

Gómez-Baggethun, E., \& Barton, D. N. (2013). Classifying and valuing ecosystem services for urban planning. Ecological Economics, 86, 235-245. doi:https://doi.org/10.1016/j.ecolecon.2012.08.019

Greenkeeper. (2019). How will Greenkeeper work? Retrieved from http://www.greenkeeperuk.co.uk/how-will-greenkeeper-work/ 
Hansen, R., Olafsson, A. S., van der Jagt, A. P. N., Rall, E., \& Pauleit, S. (2019). Planning multifunctional green infrastructure for compact cities: What is the state of practice? Ecological Indicators, 96, 99-110. doi:https://doi.org/10.1016/j.ecolind.2017.09.042

Isely, E. S., Isely, P., Seedang, S., Mulder, K., Thompson, K., \& Steinman, A. D. (2010). Addressing the Information Gaps Associated with Valuing Green Infrastructure in West Michigan: INtegrated Valuation of Ecosystem Services Tool (INVEST). Journal of Great Lakes Research, 36(3), 448-457, 410.

Jayasooriya, V. M., \& Ng, A. W. M. (2014). Tools for Modeling of Stormwater Management and Economics of Green Infrastructure Practices: a Review. Water, Air, \& Soil Pollution, 225(8), 2055. doi:10.1007/s11270-014-2055-1

Kim, G., Miller, P. A., \& Nowak, D. J. (2018). Urban vacant land typology: A tool for managing urban vacant land. Sustainable Cities and Society, 36, 144-156. doi:https://doi.org/10.1016/j.scs.2017.09.014

Lee, A. C. K., Jordan, H. C., \& Horsley, J. (2015). Value of urban green spaces in promoting healthy living and wellbeing: prospects for planning. Risk management and healthcare policy, 8, 131-137. doi:10.2147/RMHP.S61654

Liekens, I., Broekx, S., Smeets, N., Staes, J., Van der Biest, K., Schaafsma, M., . . Cerulus, T. (2013). Chapter 19 - The Ecosystem Services Valuation Tool and its Future Developments**Based on Environmental Impact Assessment Review, Broekx S., et al., "Environmental Impact Assessment Review," 65-74 (C) 2013 with permission of Elsevier. In S. Jacobs, N. Dendoncker, \& H. Keune (Eds.), Ecosystem Services (pp. 249-262). Boston: Elsevier.

Liu, P., Jiang, S., Zhao, L., Li, Y., Zhang, P., \& Zhang, L. (2017). What are the benefits of strictly protected nature reserves? Rapid assessment of ecosystem service values in Wanglang Nature Reserve, China. Ecosystem Services, 26, 70-78. doi:https://doi.org/10.1016/j.ecoser.2017.05.014

Lizin, S., Brouwer, R., Liekens, I., \& Broeckx, S. (2016). Accounting for substitution and spatial heterogeneity in a labelled choice experiment. Journal of Environmental Management, 181, 289-297. doi:https://doi.org/10.1016/j.jenvman.2016.06.038

Lyytimäki, J., \& Sipilä, M. (2009). Hopping on one leg - The challenge of ecosystem disservices for urban green management. Urban Forestry \& Urban Greening, 8(4), 309-315. doi:https://doi.org/10.1016/j.ufug.2009.09.003

Maebe, L., Claessens, H., \& Dufrêne, M. (2019). The critical role of abiotic factors and human activities in the supply of ecosystem services in the ES matrix. One Ecosystem, 4.

Martino, S., \& Muenzel, D. (2018). The economic value of high nature value farming and the importance of the Common Agricultural Policy in sustaining income: The case study of the Natura 2000 Zarandul de Est (Romania). Journal of Rural Studies, 60, 176-187. doi:https://doi.org/10.1016/j.jrurstud.2018.04.002

Matthews, T., Lo, A. Y., \& Byrne, J. A. (2015). Reconceptualizing green infrastructure for climate change adaptation: Barriers to adoption and drivers for uptake by spatial planners. Landscape and Urban Planning, 138, 155-163. doi:https://doi.org/10.1016/j.landurbplan.2015.02.010

McPherson, E. G., \& Rowntree, R. A. (1993). Energy conservation potential of urban tree planting. Journal of Arboriculture, 19, 321-321.

Millennium Ecosystem Assessment. (2005). Living beyond our means: natural assets and human well-being. Retrieved from Washington D.C.: 
O’Donnell, E. C., Lamond, J. E., \& Thorne, C. R. (2017). Recognising barriers to implementation of Blue-Green Infrastructure: a Newcastle case study. Urban Water Journal, 14(9), 964-971.

Ozdemiroglu, E., Corbelli, D., Grieve, N., Gianferrara, E., \& Phang, Z. (2013). Green Infrastructure - valuation tools assessment. Natural England: Worcester, UK.

Papadimitriou, F., \& Mairota, P. (1996). Spatial scale-dependent policy planning for land management in southern Europe. In Global to Local: Ecological Land Classification (pp. 47-57): Springer.

Pauleit, S., Ambrose-Oji, B., Andersson, E., Anton, B., Buijs, A., Haase, D., . . Konijnendijk van den Bosch, C. (2018). Advancing urban green infrastructure in Europe: Outcomes and reflections from the GREEN SURGE project. Urban Forestry \& Urban Greening. doi:https://doi.org/10.1016/j.ufug.2018.10.006

Plummer, M. L. (2009). Assessing benefit transfer for the valuation of ecosystem services. Frontiers in Ecology and the Environment, 7(1), 38-45.

Raudsepp-Hearne, C., Peterson, G. D., \& Bennett, E. M. (2010). Ecosystem service bundles for analyzing tradeoffs in diverse landscapes. Proceedings of the National Academy of Sciences, 107(11), 5242-5247.

Rodríguez, J., Beard Jr, T. D., Bennett, E., Cumming, G., Cork, S., Agard, J., . . Peterson, G. (2006). Trade-offs across space, time, and ecosystem services. Ecology and society, $11(1)$.

Rosenzweig, C., Solecki, W., Hammer, S. A., \& Mehrotra, S. (2010). Cities lead the way in climate-change action. Nature, 467, 909. doi:10.1038/467909a

Roy, A. H., Wenger, S. J., Fletcher, T. D., Walsh, C. J., Ladson, A. R., Shuster, W. D., . . . Brown, R. R. (2008). Impediments and Solutions to Sustainable, Watershed-Scale Urban Stormwater Management: Lessons from Australia and the United States. Environmental Management, 42(2), 344-359. doi:10.1007/s00267-008-9119-1

Shackleton, C. M., Blair, A., De Lacy, P., Kaoma, H., Mugwagwa, N., Dalu, M. T., \& Walton, W. (2018). How important is green infrastructure in small and medium-sized towns? Lessons from South Africa. Landscape and Urban Planning, 180, 273-281. doi:https://doi.org/10.1016/j.landurbplan.2016.12.007

Thorne, C. R., Lawson, E. C., Ozawa, C., Hamlin, S. L., \& Smith, L. A. (2018). Overcoming uncertainty and barriers to adoption of Blue-Green Infrastructure for urban flood risk management. Journal of Flood Risk Management, 11, S960-S972.

Toledo, D., Briceño, T., \& Ospina, G. (2018). Ecosystem service valuation framework applied to a legal case in the Anchicaya region of Colombia. Ecosystem Services, 29, 352-359. doi:https://doi.org/10.1016/j.ecoser.2017.02.022

van der Jagt, A. P. N., Smith, M., Ambrose-Oji, B., Konijnendijk, C. C., Giannico, V., Haase, D., ... Cvejić, R. (2019). Co-creating urban green infrastructure connecting people and nature: A guiding framework and approach. Journal of Environmental Management, 233, 757-767. doi:https://doi.org/10.1016/j.jenvman.2018.09.083

von Essen, M., do Rosário, I. T., Santos-Reis, M., \& Nicholas, K. A. (2019). Valuing and mapping cork and carbon across land use scenarios in a Portuguese montado landscape. PloS one, 14(3), e0212174-e0212174. doi:10.1371/journal.pone.0212174

Ward Thompson, C. (2011). Linking landscape and health: The recurring theme. Landscape and Urban Planning, 99(3), 187-195. doi:https://doi.org/10.1016/j.landurbplan.2010.10.006 
Wihlborg, M., Sörensen, J., \& Alkan Olsson, J. (2019). Assessment of barriers and drivers for implementation of blue-green solutions in Swedish municipalities. Journal of Environmental Management, 233, 706-718. doi:https://doi.org/10.1016/j.jenvman.2018.12.018

Wild, T. C., Henneberry, J., \& Gill, L. (2017). Comprehending the multiple 'values' of green infrastructure - Valuing nature-based solutions for urban water management from multiple perspectives. Environmental Research, 158, 179-187.

doi:https://doi.org/10.1016/j.envres.2017.05.043 
